\title{
Précis of Being for Beauty: Aesthetic Agency and Value
}

\section{Dominic McIver Lopes}

Until the middle of the last century, much work on value gave pride of place to aesthetic value. G. E. Moore named beauty alongside friendship as by far the two greatest intrinsic goods, and C. I. Lewis devoted much of his Analysis of Knowledge and Valuation to the place of the pursuit of beauty among the ends of life. ${ }^{1}$ Yet, by the 1960 , aesthetic value had largely disappeared from the agenda in philosophy. Maybe the moral shock of the second world war made it seem a diversion, or maybe the admonitions of the logical positivists made it seem intractable. Another conjecture spurs Being for Beauty. Aesthetic value has been off the agenda in philosophy in the sense that the party line, never defended, just taken for granted, is aesthetic hedonism, and aesthetic hedonism was only going to own a piece of the stage in value theory during the heyday of general value hedonism. Being for Beauty articulates and defends a new theory, the network theory of aesthetic value. In doing so, it aims to rekindle work on aesthetic value and to offer some insight into value and practical reasons more generally.

The main argument for the network theory is a limited, contrastive argument to the best explanation. The argument is limited because there is no consensus in philosophy on what needs explaining. Some explananda are therefore proposed, in the hope of generating a discussion of whether the list is correct and complete. Limited arguments are tentative about explananda. The argument is contrastive because a case is made only that the network theory is superior to aesthetic hedonism, which is the only competition for now.

According to aesthetic hedonism, an aesthetic value is a property of an item that stands in constitutive relation to finally valuable experiences of those who correctly understand the item. Being vivid is an aesthetic value. The vividness of Cantor's Diagonal Proof is

\footnotetext{
${ }^{1}$ Moore 1903, Lewis 1946.
} 
identical to or grounded in some of its other properties, ones that merit or dispose or induce those who understand it to respond with pleasure. Throughout the book, finally valuable experiences are called "pleasures," with the understanding that pleasures are intellectual as well as sensory or affective. ${ }^{2}$

Arguments bring out what is at stake in a position, so the lack of arguments for aesthetic hedonism is a problem for it. In the circumstances, Being for Beauty reads contemporary strands of aesthetic hedonism against a background of general commitments that it shares as common ground with the network theory.

First is a distinction between aesthetic value and artistic value. Aesthetic value is found in works of art but also in nature, design, games and sports, religion, and the world of ideas. In addition, many artistic values are not aesthetic - they are moral, political, cognitive or practical instead. Nowadays, too many philosophers who acknowledge these points still use "artistic" and "aesthetic" interchangeably, and still gravitate to works of art for examples. Aesthetics must make sense of all sides of aesthetic life.

Second, a theory of aesthetic value might answer two questions. A proof's vividness is an aesthetic value, but not a journalist's integrity or an activist's courage. The demarcation question asks what makes some values distinctively aesthetic. ${ }^{3}$ However, knowing what makes the proof's vividness an aesthetic value leaves open what makes it the case that its being vivid gives anyone reason to do anything. The normative question asks what makes it the case that an item's aesthetic value gives anyone reason to do anything. Only the normative question is addressed by the network theory and contemporary versions of aesthetic hedonism. Both punt on demarcation. To operationalize punting on demarcation, Being for

${ }_{2}^{2}$ Stecker 2019 misreads the book as attributing to aesthetic hedonists a narrow view of pleasure.

3 In the book, the demarcation question is called the "aesthetic question." 
Beauty adopts a working conception: a value is aesthetic when it is a paradigm aesthetic value. The idea is to stick with uncontroversial cases for the time being.

Third, the network theory and aesthetic hedonism answer the normative question in a way that is at home in the standard framework for thinking about practical reasons. Aesthetic reasons are worldly facts, such as the fact that the proof is vivid. Facts such as these are empirical or theoretical reasons, but they are also practical reasons. They lend weight to the proposition that A should $\varphi$ in C. Thus the fact that the proof is vivid lends weight to the proposition that Aisha should appreciate it in some circumstances. What explains her actually appreciating it is that she evaluates it as vivid. Her evaluating it as vivid is a motivating reason. Aesthetic acts are ones motivated by aesthetic evaluations. The book captures all this common ground in three framing assumptions:

EVALUATION: a state is an aesthetic evaluation = the state is a mental representation of some item as having some aesthetic value.

ACT: A's $\varphi$ ing is an aesthetic act $=$ A's $\varphi$ ing counterfactually depends on the content of A's aesthetic evaluation of $\mathrm{x}$, where A's ping operates on $\mathrm{x}$.

REASON: the fact that $\mathrm{x}$ is $\mathrm{V}$ is an aesthetic reason for $\mathrm{A}$ to $\varphi$ in $\mathrm{C}$ $=$ the fact that $\mathrm{x}$ is $\mathrm{V}$ lends weight to the proposition that $\mathrm{A}$ aesthetically should $\varphi$ in $\mathrm{C}$.

To answer the normative question is to give an informative reduction of the right hand side of REASON, one that completes the schema:

an aesthetic value, $\mathrm{V}$, is reason-giving = the fact that $\mathrm{x}$ is $\mathrm{V}$ lends weight to the proposition that...

Aesthetic hedonism naturally fills in the dots. Since being vivid stands in constitutive relation to pleasure, it lends weight to the 
proposition that Aisha should appreciate it in C. Appreciating the proof delivers the pleasure, and anyone always has (maybe not decisive) reason to do what delivers pleasure. Aesthetic hedonists nowadays answer the normative question by appeal to plain vanilla hedonic normativity.

Finally, to some explananda. Being for Beauty opens with case studies of several aesthetic experts, who perform reliably well, solving problems through their aesthetic activities. They are a gardener and her grandson, who restored the garden to life, a photographer who promoted the work of her predecessor, a talk show host who started a book club (you can guess), a video game source code sleuth, and a dance educator. Six observations about these cases need explaining. Aesthetic experts hail from almost all demographic niches, they jointly cover the whole aesthetic universe, they specialize by aesthetic domain (gardens vs photography), they specialize by activity (restoring vs promoting), where specialization by activity and domain interact (restoring gardens vs restoring games; making photographs vs promoting photographs); and their expertise is relatively stable. 4

Philosophers working in aesthetics will be surprised by the case studies and the explananda. The prevalent image of the aesthetic expert is a consummate appreciator and critic, a Bernard Berenson or an F. R. Leavis. The demographics of the prevalent image are terrible, and it stems from two errors. One is to confuse aesthetic evaluation with aesthetic appreciation. Beginner mathematicians might judge, based on testimony, that the Diagonal Proof is vivid and yet be unable to appreciate it. Confusing aesthetic evaluation with aesthetic appreciation occasions a second error, which takes all aesthetic acts to be or to involve acts of appreciation. In truth, a source code sleuth needs to evaluate the game she's working on,

4 Stecker 2019 offers a seventh, that "human beings appear to have always pursued aesthetic value going back to prehistory." This fact is encompassed in the first explanandum and is specifically leveraged in chapter 6. 
typically without playing the game. Although aesthetic hedonism encourages both errors, it commits to neither. So, the book assumes as common ground a distinction between appreciation and evaluation and the wide view of aesthetic acts that the distinction opens up.

Whereas the best versions of aesthetic hedonism are consistent with most of the explananda, the network theory predicts all six. Here is the official statement:

an aesthetic value, $\mathrm{V}$, is reason-giving = the fact that $\mathrm{x}$ is $\mathrm{V}$ lends weight to the proposition that it would be an aesthetic achievement for some $\mathrm{A}$ to $\varphi$ in $\mathrm{C}$, where $\mathrm{x}$ is an item in an aesthetic practice, $K$, and A's competence to $\varphi$ is aligned upon an aesthetic profile that is constitutive of $\mathrm{K}$.

Commentators remark that the theory packs in many moving parts! Start with achievement. To achieve is to perform an act successfully, as a result of competence. 5 Right there we have the key ingredient of an answer to the normative question. Anyone who acts at all thereby has reason to succeed and to use their competence to succeed. So, if the fact that a proof is vivid lends weight to its being an achievement for Aisha to appreciate it, she has reason thereby to appreciate it. The network theory answers the normative question by appeal to plain vanilla practical normativity.

Obviously, the first clause of the reduction does not predict the explananda; the task is to show how the achievement clause generates the rest of the theory. As we saw, there are many types of aesthetic act - editing and restoring, not just appreciating. Each acttype has characteristic success conditions and exploits different skills. Suppose you take and promote photographs. You have different aims and must bring different skills to bear. Your having reason to achieve as a photographer and as a promoter is thereby reason for you to take photographs of a kind that you can promote

5 This minimal achievement. Other, more involved, phenomena are also described as achievements. See Bradford 2015. 
and to promote in a way that fits the photographs you take. Since that is demanding, you have achievement-based reason to specialize in one activity and find a partner who specializes in the other. For that to work, you and your partner must be on the same page aesthetically. You must agree on the aesthetic profile of the photographs (modernist, not pictorialist, for example). Indeed, you must be so coordinated around the same aesthetic profile that your joint activities are explained by appeal to a norm to comply in a relatively stable way with the aesthetic profile. You are now in a social practice wherein your reason to achieve is often enough reason to comply with the norm. Finally, your reason to achieve in this way drives more specialization. The practice comes to be populated by agents with many different kinds of expertise. They specialize by refining the aesthetic profile, which leads to more specialized aesthetic domains - the profile of photographs splits into pictorialist versus modernist, modernism splits into the mode of the decisive moment versus that of revealing formalism, and so on. Members of any social group, interacting non-aesthetically, will have reason to step onto the aesthetic specialization escalator. Plain vanilla practical normativity predicts the six explananda.

The main argument for the network theory, namely that it handles the six explananda better than aesthetic hedonism, is meant to persuade, and also to enrich the pool of resources we have to think about aesthetic value. The distinction between demarcation and normativity, the application of the standard meta-normative framework, and the six explananda give us far more to work with than we ever had when we just took aesthetic hedonism for granted. In the same spirit, the final chapters of the book offer five bonus arguments for the network theory that empower thinking about aesthetic value.

Chapter 8 , on aesthetic motivation, takes the sting out of the implication that aesthetic value is not tied constitutively to pleasure. It also makes a case for aesthetic reasons externalism, the thesis that the fact that the proof is vivid is reason for Aisha to appreciate it 
even if she cannot be motivated to appreciate it by her evaluating it as vivid.

Certain worries about disagreement galvanize traditional thinking about aesthetic value. ${ }^{6}$ Chapter 9 articulates the worries and dispels them by showing how they miss the key role that disagreement plays in smoothing aesthetic interaction by establishing, and also modifying, the profiles of aesthetic practices.

Likewise, chapter 10 tackles the tradition's worries about the response-dependence of aesthetic values. Distinguish two facts:

1. the proof is vivid

2. (1) is an aesthetic reason.

The normative question asks what it is about vividness that makes (2) the case, and the network theory answers by reducing aesthetic normativity to plain vanilla practical normativity. But is (1) a response-dependent fact? No. The proof's vividness is grounded in its other features, not in features of us. Granted, the grounding comes with a social practice, and facts about us ground the fact that the practice is our practice. However, what we have is the fact that $\mathrm{x}$ is $\mathrm{V}$ is grounded in the fact that $\mathrm{x}$ is $\mathrm{F}$, and, in addition, the fact that that whole fact (that the fact that $\mathrm{x}$ is $\mathrm{V}$ is grounded in the fact that $\mathrm{x}$ is F) is grounded by facts about us. From this it does not follow that facts about us ground the fact that $\mathrm{x}$ is $\mathrm{V}$.

Two closing chapters mull what draws us into aesthetics in the first place. We want to know how engaging with beauty contributes to a life that goes well. Chapter 11 answers that achievement-based engagement in aesthetic practices sources meaning and well-being for individuals. Chapter 12 moves from the individual to the collective level, scouting the reasons we have to support aesthetic practices of which we are not members. Aesthetic goods are collective as well as personal goods.

For centuries, philosophical attitudes to beauty have swung from overblown and even rapturous glorification to neglect or suspicion.

${ }^{6}$ See Kivy 2015. 
Swings as wild as these cannot capture the truth about our aesthetic lives, where epiphanies and disasters are rare but where modest goods abound. The deepest commitment of Being for Beauty is to bracket the outliers and make sense of where the data points mass. We have an opportunity to get a better grip on values and reasons in general by studying one domain where values and their practical entanglements are concrete but also unencumbered by weighty authorities, the sting of reactive attitudes, and the pressure of emergencies.

\section{References}

Bradford, Gwen. 2015. Achievement. Oxford: Oxford University Press.

Kivy, Peter. 2015. De Gustibus: Arguing about Taste and Why We Do It. Oxford: Oxford University Press.

Lewis, C. I. 1946. An Analysis of Knowledge and Valuation. La Salle: Open Court.

Moore, G. E. 1903. Principia Ethica. Cambridge: Cambridge University Press.

Stecker, Robert. 2019. Review of Dominic McIver Lopes, Being for Beauty: Aesthetic Agency and Value, Notre Dame Philosophical Reviews < https://ndpr.nd.edu/news/being-for-beauty-aestheticagency-and-value $>$. 